\title{
The Effect of Outdoor Classroom Activity to the Writing Skill for Students English Department
}

\author{
Rauldatul Husni \\ English Education, University of Dharmas, Indonesia \\ rauldatulhusni@undhari.ac.id
}

\begin{abstract}
Keywords:

Outdoor Classroom;

Activity;

Writing Skill.

This research is concerned with The Effect of Outdoor Classroom Activity to the Writing Skill for student's English department Universitas of Dharmas Indonesia. The objective of this research is to find out whether there is a significant difference in teaching writing skills between the students who are taught by using outdoor classroom activity and those who are not taught by using outdoor classroom activity. The implement of outdoor classroom activity in teaching learning process especially in writing skills can be assumed students' knowledge through the solid situation such as caring students outdoor the classroom so that the students can analyze their minds through what they observe and examine precisely. Hence, this research used an experimental research that was taken at first semester students' English Department. The experimental research involved two classes of students. The sample of this research was taken randomly. Both classes were provide pre-test and post-test. Next, the students of the group were learned by proving outdoor classroom activity at the same time the control group is learned beyond outdoor classroom activity. The occur of this research, as chases: The analysis occur of the experimental class offers that the mean count of the pre-test is 45.47 and the means count of the post-test is 71.82 . It offers that the experimental class can improve student writing skill in learning process.
\end{abstract}

Article History:

Received: 25-10-2019

Revised : 27-12-2019

Accepted: 29-12-2019

Online : $30-12-2019$

\author{
This is an open access article under the CC-BY-SA license \\ Crossret \\ https://doi.org/10.31764/ijeca.v2i3.2110
}

\section{A. INTRODUCTION}

Writing most important skills of study English Language that students should be master. Based on the expert writing is a productive skill to which careful attention must be paid, and teaching such skills needs special training to make the process of learning more active and effective (Umar, 2018).

Written text has any representative that divided writing from speaking. Aside from variation in grammar, vocabulary, there are issues of letter, word, and text formation, manifested by handwriting, spelling, and layout and punctuation. Many students whose native language orthography is very disparate from English have difficulty gardening English letters. Such students necessary special distending.

Wallace et al., (2014) said that writing is the ultimate product of any divided acts that are truly demand to learn altogether. Among these divisible exploit are note-taking, identifying a central idea, outlining, drafting and editing. Both young and old students 
can appointment the disappointing "writer's block" whenever they employ in other than one or two of these activities at one time.

It is crucial to start writing an information, for instance, beyond a key concept and report to device it. Frequently, the more itemized an outline, the obvious is the writing. People commonly find that they can defeat rapid by writing the first outline swiftly and then rewrite and repair this outline.

Based on the comment over, most second language students have problem in teaching English language, notably in writing skills (Barbee, 2010). To support students writing, teachers should develop, devise or design a favorable learning model or learning activity to employ students, that they will be more interested and intrusive in the process of learning.

Outdoor classroom activity and writing skill acquire able acquaintance in serving build students discerning, even though an outdoor classroom activity plainly is a way to support students in learning process, the greatest crucial element that an outdoor classroom activity supply students convenience to guess based on what they observe in the situation around them (Nundy et al., 2009). It means the students do not only learn in a classroom activity although can stroll around in the outside conditions to explore those imaginations. The teachers create students all over such as ancient sites or recreation facilities and profuse other location that fund students with knowledge that they can use to examine their creativity and ingenuity. Applying an outdoor classroom activity in educate writing skills a process of building students' ability through expedition in their actual life to motivate ingenuity and creativity seeing that students mind be more active, effective, progressive in the teaching learning process (Aslan, 2009). This considerate of learning can be realized outside of the classroom seeing that students can associate with the condition respecting whatever they observe or the situations in which they find themselves.

O'Donnell et al., (2006) stated that Education outside the Classroom (EOtC) is a structured learning experience that takes place outside a classroom environment, during the school day, after school or during the holidays. According to Nundy (Nundy et al., 2009) Outdoor classroom activity is an outdoor academic aptitude that can be advance into a relied on study area for educators, students and masses obsessed in the innate conditions. All subjects or vulnerable can be conferred in learning an outdoor classroom activity. Outdoor classrooms further contribute substitute for all to rise a greater intelligence of what innate resources also recognize the correlation of these supplies. Probability are usable in an outdoor classroom learning to inform youth on the substance of taking care of the condition.

An outdoor classroom activity give a probability to facility innate and personal created of the situation in a usual distance. It is an instrument that avow educators to return a hands on way and progress their academic curriculum outdoors classroom. It can be concluded that outdoor classroom activity is a way of learning process involve to lead students outdoor the classroom so whereas the students can learn with the innate situation at the school.

Activities outside the classrooms can improve student and make their understand through students will be easy to write about existence they have braved exactly. Based on these ideas, the researcher would like to examine this process by determining the effectiveness of using an outdoor classroom activity to teach writing skills. 


\section{B. METHODS}

This is quantitative research and uses an experiment research. Based on Lee (Lee, 2007) stated that an experimental research indicate to a design for select and give a responsibility to subjects by conditions and statistical analysis accomplice with that procedure. In experimental designs, two or spare groups are correlated, one of which use the experimental group perceive the experimental treatment, while the other one use the control group does not give treatment. Experimental studies primarily use a pretest experiment post-test design (Creswell, 2014). Subjects are randomly nominated to groups, protecting essential intolerance.

Both groups are pre-test utilizing a appropriate consequence measure. Next, the treatment is supervised precisely, and a post-test organized. A researcher can regard at whether the outcomes modify between the experimental group and control group (Daniel, 2016). In this research, two groups of students were used. One was the experimental group, and the second was the control group. In the experimental group, outdoor classroom activity was started, and in the control group, the conventional method was started

The statistic technique in this research could be used to gather, data, including a test, questionnaire, observation and documentation (Leavy, 2017). In this research, the researcher used a test as a technique to collect the data. Pre- tests and post-tests were given to the experimental group and control group. The outcome of the tests were distinguished to determine differences between experiment and control groups in writing skills, if any, between the experimental group and the control group based on the instructional method. The test in this research measured students' writing skills between two groups, those taught by the conventional method and those taught by the outdoor classroom activity.

\section{RESULT AND DISCUSSION}

\section{Descriptive Analysis}

The descriptive analysis examined the English test scores for those taught by applying outdoor classroom activity (experimental group) and that taught without outdoor classroom activity (control group), and compared both sets of variables. The comparisons were broken down into measures of centrality and measures of dispersal for each variable.

The second groups' students Universitas of Dharmas Indonesia comprised 2 groups. They were group a containing 34 students who were the experimental group, and group B containing 34 who were the control group.

a. Pre-test of experimental group

The data were evaluate by using SPSS 20. Explanatory data statistics for the experimental group containing the mean score, median score, mode score, and standard deviation score. The data allocation in the pre-test of the experimental group fair 15 students who acquire scores among 34-36 or $44 \%, 4$ students who acquire scores among 37-39 or $11 \%$, nobody acquire score among 40-48 or $0 \%, 1$ student who acquire a score among 49-51 or $2 \%, 2$ students who acquire scores among 52- 54 or 5\%, 2 students who acquire scores among 55-57 or 5\%, 6 students who acquire scores among 58- 60 or 17\%, and nobody who acquire a score among $61-63$ or $0 \%$, 3 students who acquire scores among 64-66 or 8\%, nobody who acquire a score among 67-69 and the last only 1 student a score among 70-72 or $2 \%$. 


\section{b. Post-test of Experimental group}

The concise of the data allocation of the post-test in the experimental group is advertised in the issue of data allocation in the post-test of the experimental group, mean score of post-test was 71.82, the median score was 68.50 , the mode score was 90 , and the standard deviation score was 13.43. There is a significant different improve among the pre-test and the post-test score of the experimental group.

The entire number who exist in the post-test of the experimental group is 34 . the data score allocation in post-test of the experimental group fair that 1 student acquire a score among 44-47 or 2\%, 2 students acquire a score among 48-51 or 5\%, 1 student acquire a score among 52-55 or 2\%, 1 student who acquire a score among 56-59 or 2\%, 3 students who acquire a score among 60-63 or 8\%, 9 students who acquire a score among 64-67 or 26\%, 2 students who acquire a score among 68-71 or 5\%, 3 students who acquire a score among 72-75 or 8\%, nobody who acquire a score among 76-79 with $0 \%, 2$ students who acquire scores among $80-83$ or $5 \%, 1$ student who acquire a score among $84-87$ or $2 \%$, and 9 students who acquire scores among $88-91$ or $26 \%$.

Some resemblance can be fixed that the pre-test of the experimental group distribution of mean score was 45.47 , the median score was 37.00 , the mode score was 34.00 and the standard deviation score was 12.89 . And the average in the post-test of the experimental group is the mean score was 71.82, the median score was 68.50 , the mode score was 90.0 and the standard deviation score was 13.43. It can be concluded that the scores of all post-test were higher than the pre-test in the experimental group. It means that the students who are taught using outdoor classroom activity and the conventional method was different, from the data comparison above the result of the post-test score significantly improve then pre-test score of the experimental group.

c. Pre-test of Control group

The concise of the data allocation of the pre-test of the control group. In this research, the total number of the control group was 34 students. The mean score was 43.18, median score was 36.00 , mode score was 34.00 , and the standard deviation score was 11.45. Distribution of interval, frequency, and percentage in the pre-test scores of the control group.

The data allocation in the pre-test of control group fair 17 students who acquire a score among 34-36 or 50\%, 2 students who acquire a score among 37-39 or 5\%, 2 students acquire a score among 40-42 or 5\%, nobody who acquire a score among 43-45 or $0 \%, 2$ students acquire a score among 46-48 or 5\%, 2 students who acquire a score among $49-51$ or $5 \%, 3$ students who acquire a score among 55-57 or 8\%, 2 students who acquire a score among 58-60 or 5\%, nobody who acquire a score among 61-63 or $0 \%, 2$ students who acquire a score among $64-66$ or $5 \%$, nobody who acquire a score among 67- 69, and 1 student who acquire a score among 70-72 or $2 \%$.

d. Post-test in the control group

The data allocation in the post-test of control group fair 14 students who acquire scores among 34-37 or 41\%, 3 students who acquire scores among 38-41 or 5\%, nobody acquire a score among 42-45 or 2\%, 1 student acquire a score among 46-49 or 2\%, 4 students who acquire scores among 50-53 or 11\%, 3 students who acquire scores among 54-57 or 8\%,3 students who acquire scores among 58-61 or 8\%, 3 students who acquire scores among 62-65 or 8\%, nobody acquire a score among 66-69 or $0 \%$, nobody who acquire scores among 70-73 or $0 \%$, and 2 students who acquire scores among 74 77 or $5 \%$. 
The resemblance of the pre-test and post-test scores of the control group. The mean score of the pre-test was 43.18, median score was 36.00 , and mode score 34.00 and the standard deviation score was 12.45. Andin the post-test scores of the control group were: mean score was 46.88 , median score was 46.50 , mode score was 34.00 and the standard deviation score was 13.17. It can be concluded that the pre-test and post-test scores of the control group were not as acceptable as the score of the pre-test and posttest of the experimental group, it means implementation of outdoor classroom activity in teaching learning process especially in writing skill was more effective than teaching writing using a conventional method.

\section{Tests for Normalcy of the data}

To discovery out the effectiveness of teaching writing outdoor classroom activity, the researcher uses a t-test, during to test the normality of the data statistics the researcher use the theory of Kolmogrov-Smirnov to know the homogeneity of the data, the data essential be tested by using homogeneity test. The test represent below:

a. Experimental group

1) Normality Test

A normality test is used to examine whether the data allocation is normal or not. The researcher determine 0.05 for the significant test. The normality test for the pre-test in the experimental group and control group, the normality test issue of the pre-test and post-test of the experimental group, it can be represented that the score of the pre-test in the experimental group and pre-test in the control group are normal. It is consider the value of significance is higher than 0.05 . itcan be seen from Kolmogrov-Smirnov table in which the significance value of the pre-test in the experimental group is $1.266>0.05$ and the significance value of the pre-test in the control group is $0.978>0.05$. as a result, the pre-test and post-test of the experimental group are normal.

2) Homogeneity Test

The homogeneity test is used to discovery out whether the sample has the same variance or not, the research used the levene test analysis. Based on the calculation above, the significance of the students' writing skill in the pre-test and post-test for both experimental group and control group reveal the contribute of the pre-test is 0.990 . The prospect or significance for both groups is higher than 0.05 . The issue can be concluded that the score are homogeneous for the value of significance is $0.990>0.05$ and the post-test is $0.990>0.5$. as a result, the variance of the two groups in the pre-test is homogeneous and the sample has the same variance. So the data fair the specification of research analysis.

3) Hypothesis Test

To correlate the result of the pre-test among experimental and control groups the researcher has to calculation t-test. The t-test was used to test rather there are significantly different results of the two groups. The result of the t-test can be the value of $p$ or the level of significance is 0.441 . The value of $p$ is higher than tt0.05 or $0.441>0.05$ it suggest that hypothesis null is accepted. As a result, the score of the writing test among the experimental group and the control group is not significantly different in the pre-test. 
b. Control group

1) Normality test

A normality test is used to examine whether the data allocation is normal or not. The researcher determine 0.05 for the significant test. The normality test was used Kolmogrov-Smirnov test. The result of the normality test for the post-test in the experimental group and control group. Based on the data of the post-test in the experimental group and post-test in the control group are normal. It is because the score of significance is higher than 0.05. It can be seen from Kolmogrov-Smirnov table in which the significance score of the post-test in the experimental group is $1.348>0.05$ and the significance score of the post-test in the control group is $1.286>0.05$. As a result, the experimental group and control group data in the posttest are normal.

2) Homogeneity Test

The homogeneity test is used to discovery out whether the sample has the same variance or not, the test homogeneity of the variance, the researcher used the levene test analysis. Based on the computation above, the significance of the students' writing skill in the post-test reveal the contribute of 0.068 . The prospect or significance is higher than 0.05 . The issue can be concluded that the data are homogeneous because the score of significance is $0.068>0.05$. As a result, the variance of the two groups in the post-test is homogeneous and the sample has the same variance. So the data fair the specification of research analysis

3) Hypothesis Test

To correlate the result of the post-test among experimental and control group the researcher has to calculation t-test. The t-test is used to test whether there are significant different results of the two groups. The value of the level of significance is 0.000 . Lower than $t_{t} 0.000<0.05$ it means that the hypothesis null is accepted. As a result, it can be concluded that the score of the students in writing skill among the experimental group and control group is significantly different. The researcher used t-test one sample, as a result, the analysis is represented. The result of the Paired sample t-test in the pre-test of experimental and control groups in Independent $t$ test for the post-test of both experimental and control groups presented in the value of $\mathrm{p}$ is .990 it is higher than 0.5 .

Based on research finding above, the writing test of the student English department Universitas of Dharmas Indonesia who are taught using the outdoor classroom activity was higher than the scores of those students' writing test before using conventional method. Forward the treatment, the pre-test of the mean score of the experimental group was 45.57 and afterwards treatment the mean score of the post-test in experimental group was 71.82. It significantly improved, it means that outdoor classroom activity is effective in teaching writing students.

And the score writing test of those taught by the conventional method was 43.18 before they were taught using the conventional method and 46.88 after being taught by the conventional method. Hence, the conventional method was not as effective in teaching learning process especially in writing skill as an outdoor classroom activity. The outdoor classroom activity exist an effective way of teaching writing process between this group of students. It also can be seen from the result of the t-test with a value of $\mathrm{p}=0.000$ for Dependent $\mathrm{t}$-test for experimental group either using paired sample t-test in the pre-test of experimental and control groups was lower than 0.5 , and 
The result of dependent t-test for control group issue that the value of $\mathrm{p}$ is 183 . It is higher than $0.05 \quad(183>0.05)$. the issue of Independent t-test for pre-test among experimental and control group fair that the value of $p$ is .121 is higher than 0.5 and the issue of Independent t-test for post-test of both experimental and control groups fair that the value of $p$ is .990 it is higher than 0.5 . It can be concluded that the result of teaching writing using outdoor classroom activity at the student English department Universitas of Dharmas Indonesia is significantly improved then teaching writing using a conventional method. Hence, the outdoor classroom activity can forward student writing ability and create students interested to learning because they can manage their learning objective.

\section{CONCLUSION AND SUGGESTIONS}

First, teaching writing for the student's English department Universitas of Dharmas Indonesia proving the outdoor classroom activity was efficient. The score surely fair that the value of $p$ or the level of significance is 0.441 . The value of $p$ is higher than $t+0.05$ or $0.441>0.05$ it means that hypothesis null is accepted. And the score fair that the value of the level of significance is 0.000 . Under than tt $0.000<0.05$ it means that the hypothesis null is accepted. Accordingly, the score of the writing test among the experimental and the control group were not significantly different in the pre-test. The using outdoor classroom activity in writing skill was more successful in teaching learning process to students than the conventional method.

Second, many achievable interpretation occur for this learning success. The outdoor classroom activity can contribute a secure acquaintance with students and create them greater active, effective and progressive in the learning process. Next to, the outdoor classroom activity lead students not only to learn, review, and inquiry in the classroom but also to learn outside of the classroom in a more innate contemplation. Perchance, this activity can encourage students' ingenuity, intelligence, critical thinking, and improve knowledge. There are many influences to realizing outdoor classroom activity, allowing the teacher to be greater ingenious, productive, innovative and inventive in the learning process.

It is very important to create a good learning process or environment such as the outdoor classroom activity to implement in the classroom because most of the students need to develop their creativity and learn through real experiences such as bringing them out of the classroom. It will be very useful for both students and teachers to learn through what they face and see directly through their personal experiences. Besides that, students' background knowledge will be formed through real situations that they have had. The results of this research may provide a pathway for students can learn more about writing skills.

\section{ACKNOWLEDGEMENT}

The authors gratefully acknowledge the financial support from Universitas of Dharmas Indonesia, and I would like to thank the reviewers for their comments on this article. 


\section{REFERENCES}

Apriyanto, S., \& Anum, A. (2018). Gender Dynamics on Speaking Interaction in the College Classroom. Jurnal Smart, 4(2), 73. https://doi.org/10.26638/js.692.203x

Aslan, 0. (2009). The role of gender and language learning strategies in learning English. Unpublished Master's Thesis, September.

Barbee, M. (2010). Drama as Pedagogy in L2 Learning: A Literature Review. Language, Culture, Literature, 2(1), 1-25.

Creswell, J. (2014). Research design: Qualitative, Quantitative, and Mixed Methods Approaches (V. Knight (ed.); Fourth Edi). SAGE Publication. https://doi.org/10.4135/9781849208956

Daniel, E. (2016). The Usefulness of Qualitative and Quantitative Approaches and Methods in Researching Problem-Solving Ability in Science Education Curriculum. Journal of Education and Practice, 7(15), 91-100. https://doi.org/2222-288X

Leavy, P. (2017). Research Design: Quantitative, Qualitative, Mixed Methods, Arts-Based, and Community-Based Participatory Research approaches. The Guilford Press. https://books.google.com.my/books?id=hxyDDgAAQBAJ\&dq=research+design\&source=gb s_navlinks_s

Lee, H. (2007). Essentials of Behavioral Science Research: A First Course in Research Methodology. 160.

Nundy, S., Dillon, J., \& Dowd, P. (2009). Improving and encouraging teacher confidence in out-ofclassroom learning: The impact of the hampshire trailblazer project on 3-13 curriculum practitioners. Education 3-13, 37(1), 61-73. https://doi.org/10.1080/03004270802291889

O'Donnell, L., Morris, M., \& Wilson, R. (2006). Education outside the classroom: An assessment of activity and practice in schools and local authorities. National Foundation for Education Research, November, 1-117. http://www.education.gov.uk/publications/eOrderingDownload/RR803.pdf

Umar. (2018). Students ' Speaking Motivation In Learning. Premise : Journal of English Education and Applied Linguistics, 7(1), 57-67. https://doi.org/doi.org/10.24127/pj.v7i2.

Wallace, T., Stariba, W. E., \& Walberg, H. J. (2014). Teaching Speaking, Listening and Writing. International Academy of Education, May, 12-21. 